\title{
Formulasi Sediaan Salep Ekstrak Kulit Batang Cadamba (Anthocephalus cadamba Miq.) dan Aktivitas Antibakterinya Terhadap Staphylococcus aureus
}

\author{
Nur Rifka Rahmadini ${ }^{1, \dagger}$, Sabaniah Indjar Gama ${ }^{1}$, Rolan Rusli ${ }^{1,2, \text {, }}$ \\ ${ }^{1}$ Laboratorium Penelitian dan Pengembangan Kefarmasian "Farmaka Tropis", \\ Fakultas Farmasi, Universitas Mulawarman, Samarinda, Indonesia \\ †Email: Rahmadinirifka@gmail.com \\ ${ }^{2}$ Kelompok Bidang Ilmu Kimia Farmasi, Fakultas Farmasi, \\ Universitas Mulawarman, Samarinda, Indonesia \\ *Email: rolan@farmasi.unmul.ac.id
}

\begin{abstract}
Cadamba (Anthocephalus cadamba Miq.) is a fast-growing plant with many uses. Secondary metabolites contained in cadamba plants such as alkaloids, flavonoids and glycosides that have antibacterial activity. This study aims to determine the antibacterial activity of cadamba bark extract and the preparation of ointments made from cadamba extract. The results obtained showed that cadamba extract had antibacterial activity with an effective concentration of 5\%. The ointment with the active ingredient cadamba extract also has antibacterial activity. Preparations of ointments made from cadamba extract met the standard requirements for ointment preparations, which included organoleptic, dispersive power, $\mathrm{pH}$, and homogeneity.
\end{abstract}

Keywords: Anthocephalus cadamba, antibacterial, characteristic, ointment

\begin{abstract}
ABSTRAK
Cadamba (Anthocephalus cadamba Miq.) merupakan tanaman cepat tumbuh dengan banyak kegunaan. Metabolit sekunder yang terkandung dalam tanaman cadamba seperti alkaloid, flavonoid dan glikosida yang memiliki aktivitas antibakteri. Penelitian ini bertujuan untuk mengetahui aktivitas antibakteri ekstrak kulit batang cadamba dan sediaan salep berbahan aktif ekstrak cadamba. Hasil yang didapatkan menunjukkan bahwa ekstrak cadamba memiliki aktivitas antibakteri dengan konsentrasi efektif sebesar 5\%. Sediaan salep dengan bahan aktif ekstrak cadamba memiliki pula aktivitas antibaketeri. Sediaan salep berbahan aktif ekstrak cadamba memenuhi persyaratan standar untuk sediaan salep, yang meliputi organoleptis, daya sebar, $\mathrm{pH}$, dan homogenitas.
\end{abstract}

Kata Kunci: Anthocephalus cadamba, antibakteri, karakteristik, salep

DOI: https://doi.org/10.25026/mpc.v8i1.340 


\section{PENDAHULUAN}

Masyarakat indonesia sejak zaman dahulu mengenal tanaman yang mempunyai obat atau mampu menyembuhkan berbagai macam penyakit, dalam penggunaannya dikenal dengan berbagai pengobatan tradisional. Beberapa dari penelitian tentang tumbuhan cadamba menyatakan bahwa tanaman ini mengandung metabolit sekunder yang berperan sebagai antibakteri, antioksidan, antiinflamasi, antipiretik, dan antifungial yaitu alkaloid, flavonoid, triterpenoid dan glikosida. Menurut penelitian [1] ekstrak metanol kulit batang cadamba yang mempunyai aktivitas antibakteri yaitu mengandung alkaloid, flavonoid dan glikosida.

Antibakteri adalah zat yang membunuh atau menekan pertumbuhan atau reproduksi bakteri. Zat antibakteri berdasarkan efek yang dihasilkan terhadap pertumbuhan bakteri yaitu bakteriostatik (menghambat) dan bakterisdal (membunuh) [1].

Kulit merupakan salah satu organ dipermukaan tubuh yang pertama terkena pengaruh tidak menguntungkan dari lingkungan. Kulit mempunyai fungsi dan kegunaan diantaranya kulit berfungsi untuk melindungi tubuh dari serangan yang disebabkan oleh mikroorganisme. Bakteri Staphylococcus aureus merupakan bakteri yang hidup dipermukaan tubuh individu sehat tanpa membahayakan. Namun, ketika kulit kita mengalami luka atau tusukan, bakteri ini akan masuk melalui luka dan menyebabkan infeksi [2].

Sediaan salep lebih cocok dan digunakan untuk terapi penyakit kulit yang disebabkan oleh bakteri. Salep adalah sediaan setengah padat yang mudah dioleskan dan hanya digunakan sebagai obat luar. Basis salep yang digunakan dalam sebuah formulasi obat harus bersifat inert dengan kata lain tidak merusak ataupun mengurangi efek terapi dari obat yang dikandungnya [3].
Penelitian ini bertujuan untuk mengetahui Konsentrasi Hambat Minimal (KHM) ekstrak A. cadamba yang berpotensi sebagai antibakteri, mengetahui manakah formula basis salep yang optimal dan memenuhi kriterian sediaan yang baik, dan mengetahui apakah sediaan salep $A$. cadamba memiliki aktivitas antibakteri sebagai obat infeksi kulit.

\section{METODE PENELITIAN}

\section{Proses Ekstraksi dan Fraksinasi}

Sampel kulit batang cadamba (2 $\mathrm{kg})$, diambil dari Desa Liang Kecamatan Kota Bangun Kabupaten Kutai Kartanegara, Kalimantan Timur, Indonesia. Kulit batang cadamba dicuci bersih, di oven $50^{\circ} \mathrm{C}$ selama 2 hari. Kemudian di potong kecil-kecil dan diblender. Simplisia kulit batang cadamba 200 gram yang telah dirajang dimaserasi menggunakan pelarut metanol 3,5 L selama 3 hari. Sampel kemudian dipekatkan menggunakan alat rotary evaporator suhu $50^{\circ} \mathrm{C}$. Ekstrak tersebut dilanjutkan proses fraksinasi menggunakan pelarut air:n-heksan dengan perbandingan 1:1. Ekstrak ditimbang 10 gram kemudian ekstrak tersebut dilarutkan dengan aquades 50 $\mathrm{mL}$ dan dimasukkan n-heksan $50 \mathrm{~mL}$ kedalam corong pisah, kemudian digojok. Didiamkan 1x24 jam hingga terbentuk 2 fase. Ditampung dan diuapkan fraksi ekstrak air sampai diperoleh eksrak kental dan diuji aktivitas antibakterinya.

\section{Pembuatan Variasi Konsentrasi}

Ekstrak fraksi air kulit batang cadamba yang diuji untuk menghambat pertumbuhan bakteri Staphylococcus aureus dibuat dalam konsentrasi yaitu $5 \%-25 \% \mathrm{~b} / \mathrm{v}$.

\section{Skrinning Fitokimia}

Ekstrak kulit batang cadamba ditambahkan $\mathrm{HCl}$ pekat kemudian ditambahkan serbuk $\mathrm{Mg}$ menjadi 
perubahan warna jingga pada tabung yang menandakan ekstrak mengandung flavonoid. Pengujian alkaloid ekstrak kulit batang cadamba dilarutkan dengan $\mathrm{HCl} 2 \mathrm{~N}$ dan diberi pereaksi wagner sebanyak 3 tetes, terbentuknya endapan warna merah kehitaman menunjukkan ekstrak mengandung alkaloid.

\section{Pengujian Antibakteri}

\section{Pembuatan medium NA (Nutrient Agar)}

Medium NA 5,25 gram dilarutkan menggunakan aquades pada erlenmeyer $250 \mathrm{~mL}$. Dipanaskan medium hingga larut sempurna, kemudian di sterilisasi.

\section{Sterilisasi}

Sterilisasi alat (cawan petri, tabung reaksi, tube mikropipet, paper disk) dan medium untuk pengujian antibakteri dengan terlebih dahulu dibungkus kertas kemudian di sterilisasi menggunakan autoklaf suhu $121^{\circ} \mathrm{C}$ selama 1,5 jam.

\section{Pembiakan bakteri}

Medium NA $5 \mathrm{~mL}$ dimasukkan kedalam tabung reaksi steril dimiringkan dan dibiarkan memadat. Setelah memadat di inokulasi bakteri Staphylococcus aureus dari biakkan murni menggunakan ose bulat. Inkubasi ke dalam inkubator suhu $37^{\circ} \mathrm{C}$ selama 24 jam.

\section{Suspensi bakteri}

Tambahkan $9 \mathrm{ml} \mathrm{NaCl}$ kedalam biakkan bakteri yang berumur 24 jam dihomogenkan. Diambil 2,5 $\mathrm{mL}$ dimasukkan kedalam tabung steril baru kemudian ditambah $7,5 \mathrm{~mL} \quad \mathrm{NaCl}$ dihomogenkan.

\section{Pengujian antibakteri}

$10 \mathrm{~mL}$ medium NA dan $100 \mu \mathrm{L}$ suspensi bakteri dimasukkan kedalam cawan petri. Dibiarkan memadat. Setelah memadat, rendam paper disk ke dalam masing-masing konsentrasi dan diletakkan paper disk. Diinkubasi selama $1 \times 24$ jam $37^{\circ} \mathrm{C}$.

\section{Formulasi Basis Salep}

Formula basis pada penelitian ini dapat dilihat pada Tabel 1. PEG 4000 dilelehkan diatas hot plate pada suhu 50$58^{\circ} \mathrm{C}$ hingga terbentuk cairan kemudian dimasukkan PEG 400 diaduk hingga merata dan kedua bahan melebur sempurna. Kemudian campuran PEG di gerus hingga terbentuk massa salep ditambahkan aquades tetes demi tetes (secukupnya), nipagin dan nipasol dilarutkan ke dalam ekstrak, kemudian dimasukkan ekstrak ke dalam basis salep dan digerus hingga homogen.

\section{Evaluasi sediaan salep}

Pengujian evaluasi sediaan salep yang dilakukan dan diamati selama penyimpanan meliputi pengamatan berupa organoleptis, uji $\mathrm{pH}$, uji viskositas, uji daya sebar, uji daya homogenitas dan uji antibakteri sediaan.

\section{HASIL DAN PEMBAHASAN}

Ekstrak metanol kulit batang cadamba yang dihasilkan sebanyak 39,5 gram, sedangkan ekstrak hasil fraksinasi yang dihasilkan sebanyak 13,48 gram. Hasil skrining fitokimia ekstrak kulit batang cadamba mengandung metabolit sekunder alkaloid dan flavonoid. Kedua metabolit ini memiliki aktivitas sebagai antibakteri.

Pengujian aktivitas antibakteri ekstrak kulit batang cadamba dengan konsentrasi 5\%-25\% memiliki aktivitas sebagai antibakteri, untuk penghambatan bakteri tersebut dapat dilihat pada gambar 1 . 


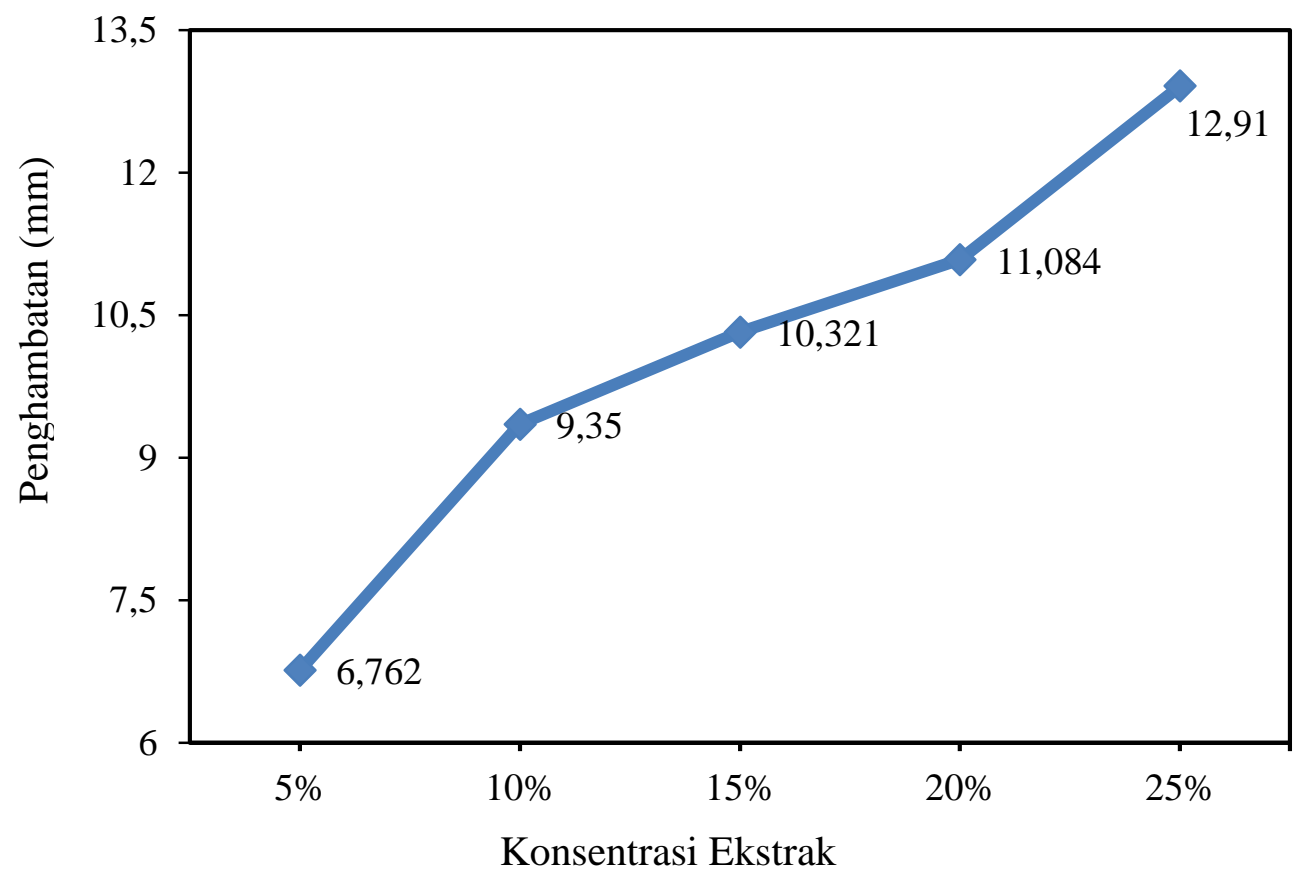

Gambar 1. Aktivitas antibakteri ekstrak kulit batang cadamba

Tabel 1. Formulasi Basis Salep

\begin{tabular}{llccc}
\hline \multirow{2}{*}{ No. } & \multicolumn{2}{|c}{ Nama bahan } & \multicolumn{3}{c}{ Formula (gram) } \\
\cline { 3 - 5 } & & F1 (30:70) & F2 (40:60) & F3 (50:50) \\
\hline 1. & PEG 400 & 2,98 & 3,98 & 4,98 \\
2. & PEG 4000 & 6,98 & 5,98 & 4,98 \\
3. & Metilparaben (nipagin) & 0,03 & 0,03 & 0,03 \\
4. & Propilparaben (nipasol) & 0,03 & 0,03 & 0,03 \\
5. & Aquades & qs & qs & Qs \\
\hline
\end{tabular}

Tabel 2. Karakteristik Fisik Basis Sediaan Salep

\begin{tabular}{lllll}
\hline No. & \multicolumn{1}{c}{ Uji } & \multicolumn{1}{c}{ F1(30:70) } & \multicolumn{1}{c}{ F2 (40:60) } & \multicolumn{1}{c}{ F3 (50:50) } \\
\hline 1. & Organoleptis & Bentuk: semi solid, & Bentuk: semi solid, \\
& & agak memadat & sedikit lunak & lunak \\
& & Bau: tidak berbau & Bau: tidak berbau & Bau: tidak berbau \\
& & Warna: putih & Warna: putih & Warna: putih \\
2. & Homogenitas & Homogen & Homogen & Homogen \\
3. & pH & 6,2 & 6,0 & 6,1 \\
4. & Daya sebar & $4,73 \mathrm{~cm}$ & $5,10 \mathrm{~cm}$ & $5,67 \mathrm{~cm}$ \\
\hline
\end{tabular}

Berdasarkan gambar 1, ekstrak kulit batang cadamba akan memiliki aktivitas antibakteri yang semakin tinggi dengan peningkatan konsentrasi. Hal ini disebabkan karena semakin besarnya zona hambat berupa zona bening di sekitar paper disk yang diperoleh. Berdasarkan zona hambat yang terbentuk 
dapat digolongkan yaitu antibakteri lemah ( $<5 \mathrm{~mm})$, antibakteri sedang (5-10 $\mathrm{mm})$, antibakteri $(10-20 \mathrm{~mm})$, dan antibakteri sangat kuat (>20 mm) [4].

\section{Berdasarkan} pengamatan organoleptis (Tabel 2) variasi basis salep berpengaruh pada bentuk, namun tidak berpengaruh pada bau dan warna. Dimana F3 memiliki massa salep paling lunak dibandingkan F1 yang bentuknya agak memadat dan F2 yang bentuknya sedikit lunak.

Pengujian homogenitas salep dilakukan secara visual untuk menunjukkan hasil yang homogen yang ditandai dengan tidak adanya butiran kasar pada kaca preparat dan menyebar secara merata. Hasil uji homogenitas dapat dilihat pada tabel 2, hal ini menunjukkan bahwa F1, F2, dan F3 tidak ada perubahan homogenitas pada sediaan. Sediaan salep harus homogen dan rata agar tidak menimbulkan iritasi dan terdistribusi merata ketika digunakan.

Pengujian $\mathrm{pH}$ bertujuan untuk mengetahui keamanan sediaan saat digunakan pada kulit. Pemeriksaan $\mathrm{pH}$ ini salah satu kriteria pemeriksaan sifat fisikkimia dan memprediksi kestabilan sediaan salep. Hasil pengujian $\mathrm{pH}$ dapat dilihat pada tabel 2 bahwa ketiga formula basis tersebut memenuhi kriteria sediaan salep yaitu $\mathrm{pH}<6,5$. Kriteria salep yang baik yaitu 4,5-6,5, Jika $\mathrm{pH}$ sediaan yang terlalu asam dapat mengiritasi kulit dan $\mathrm{pH}$ sediaan yang terlalu basa maka dapat menyebabkan kulit bersisik [5].

Hasil pengujian daya sebar sediaan salep dapat dilihat tabel 5 pada F1 $(4,73 \mathrm{~cm}), \mathrm{F} 2(5,10 \mathrm{~cm})$, dan F3 $(5,67$ $\mathrm{cm})$. Dari ketiga formula dapat terlihat bahwa F2 dan F3 telah memenuhi kriteria, sedangkan F1 tidak masuk dalam kriteria sediaan. Dari ketiga formula tersebut F3 paling luas penyebarannya daripada F2, hal ini berarti daya sebar salep memiliki konsistensi yang lebih lunak/lembek. Daya sebar menunjukkan kemampuan sediaan untuk menyebar pada kulit, semakin luas permukaan kulit tempat sediaan menyebar maka absorbsi dari bahan obat yang terkandung akan meningkat. Kriteria daya sebar sediaan salep yang yaitu baik $5-7 \mathrm{~cm}$. Hasil pengujian tersebut merupakan sediaan salep sudah memenuhi kriteria daya sebar yang nyaman bagi kulit [6].

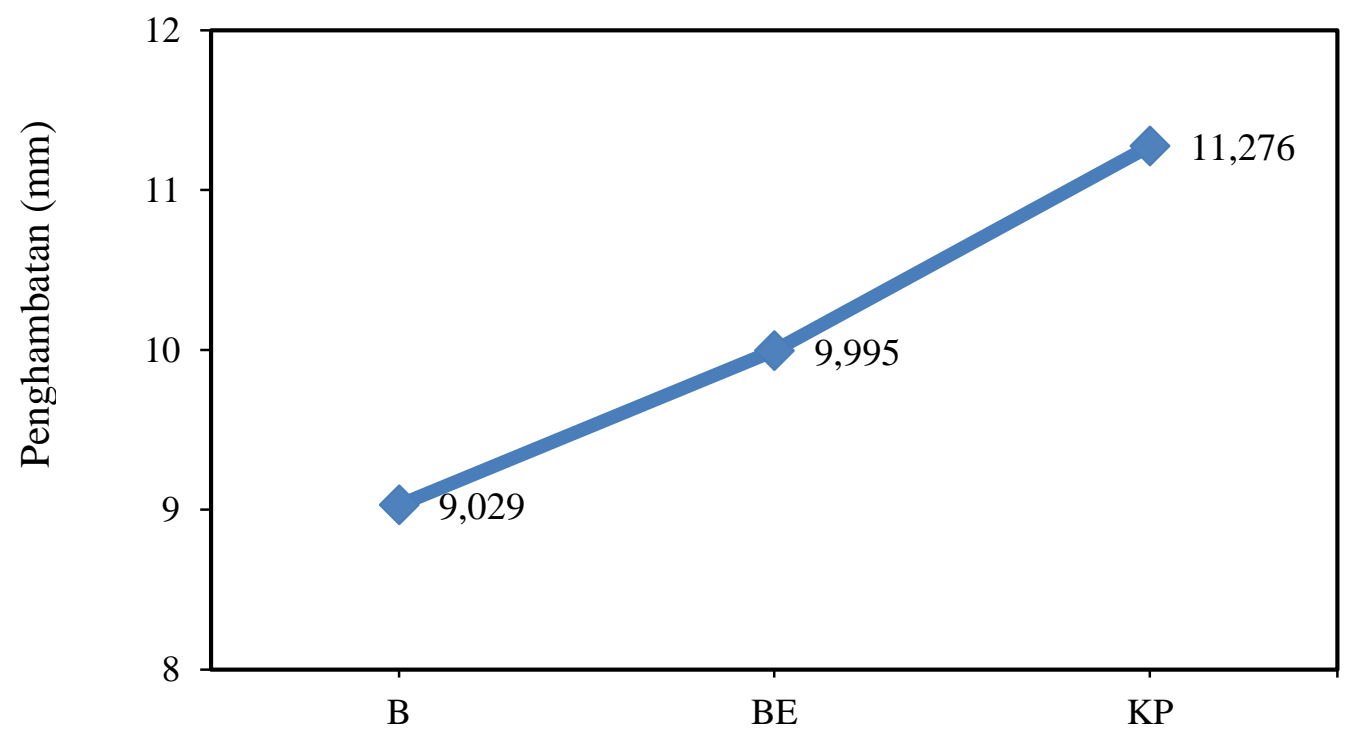

Gambar 2. Hasil pengujian antibakteri sediaan salep berbahan aktif ekstrak cadamba.

Keterangan: $\mathrm{B}=$ basis tanpa ekstrak, $\mathrm{BE}=$ basis + ekstrak, dan $\mathrm{KP}=$ Kontrol positif gentamisin 


\section{Pengujian Antibakteri Sediaan Salep Terhadap Staphylococcus aureus}

Berdasarkan Gambar 2 hasil pengujian antibakteri salep ekstrak kulit batang cadamba menunjukkan bahwa ketiga formula memiliki aktivitas antibakteri terhadap Staphylococcus aureus dengan zona hambat $(\mathrm{mm})$ yang berbeda. Pada B (basis tanpa ekstrak) memiliki aktivitas antibakteri karena basis tersebut diberi penambahan bahan pengawet dan basis berbahan dasar PEG ini bersifat bakterisida, Sedangkan pada BE (basis yang diberi ekstrak) daya hambatnya lebih besar dibandingkan B (basis tanpa ekstrak) karena ekstrak $A$. cadamba mengandung alkaloid dan flavonoid yang berpotensi sebagai antibakteri. Dibandingkan dengan KP (Kontrol positif Gentamisin) lebih besar zona hambatnya karena merupakan antibiotik golongan aminoglikosida yang efektif untuk menghambat bakteri penyebab infeksi kulit baik primer maupun sekunder seperti Staphylococcus aureus [7].

\section{KESIMPULAN}

Ekstrak kulit batang cadamba mengandung alkaloid dan flavonoid yang berpotensi sebagai antibakteri yaitu pada konsentrasi 5\%. Basis larut air berbahan dasar PEG dengan perbandingan 50:50 yang memenuhi karakteristik fisik sediaan yaitu terdiri dari organoleptis, daya sebar, $\mathrm{pH}$, homogenitas, serta pengujian antibakteri sediaan salep.

\section{DAFTAR PUSTAKA}

[1] Sari Rita K dkk, 2014. Aktivitas Antiproliferasi Ekstrak Jabon Putih (Anthocephalus cadamba Miq.) terhadap Sel Kanker Payudara dan Serviks. J. Ilmu dan Teknologi Kayu Tropis Vol. 12 No.1

[2] Misna dan Diana Khusnul, 2016. Aktivitas Antibakteri Ekstrak Kulit Bawang Merah (Allium cepa L.) Terhadap Bakteri Staphylococcus aureus. GALENIKA Journal of Pharmacy Vol. 2 No. 2

[3] Naibaho OH dkk, 2013. Pengaruh Basis Salep Terhadap Formulasi Sediaan Salep Ekstrak Daun Kemangi (Ocimum sancum L.) Pada Kulit Punggung Kelinci Yang Dibuat Infeksi Staphylococcus aureus. PHARMACON Jurnal Ilmiah Farmasi Vol. 2 No. 2

[4] Pratiwi, ST. 2008. Mikrobiologi Farmasi. Penerbit Airlangga: Yogyakarta

[5] Naibaho OH dkk, 2013. Pengaruh Basis Salep Terhadap Formulasi Sediaan Salep Ekstrak Daun Kemangi (Ocimum sancum L.) Pada Kulit Punggung Kelinci Yang Dibuat Infeksi Staphylococcus aureus. PHARMACON Jurnal Ilmiah Farmasi Vol. 2 No. 2

[6] Grag, A et al. 2002. Spreading of Semisolid Formulation: An update. Journal of Pharmaceutical Science, 55 (3).

[7] Prataya, NS dkk, 2014. Uji Efektivitas Sediaan Salep Ekstrak Daun Miana (Coleus scutellarioides L.) Untuk Pengobatan Luka Yang Terinfeksi Bakteri Staphylococcus aureus Pada Kelinci. PHARMACON Jurnal Ilmiah Farmasi Vol. 3 No. 3 